\title{
SHAKING TABLE TESTS OF A TWO-STOREY LOG HOUSE
}

\author{
Jorge M. Branco a , Paulo B. Lourenço ${ }^{\mathrm{b}}$, Chrysl A. Aranha ${ }^{\mathrm{c}}$ \\ a Assistant Professor, ISISE, Univ. of Minho, Dept. of Civil Engineering, Campus de Azurém, \\ 4810-058 Guimarães, Portugal. \\ Tel. +351 253510 200; Fax: +351 253510217 \\ E-mail: jbranco@civil.uminho.pt; Corresponding author \\ ${ }^{\mathrm{b}}$ Full Professor, ISISE, Univ. of Minho, Dept. of Civil Engineering \\ E-mail: pbl@civil.uminho.pt \\ ${ }^{c}$ PhD student, ISISE, Univ. of Minho, Dept. of Civil Engineering \\ E-mail: chryslaranha@gmail.com
}

\begin{abstract}
This paper presents the findings of an experimental campaign that was conducted to investigate the seismic behaviour of log houses. A two-storey log house designed by the Portuguese company Rusticasa ${ }^{\circledR}$ was subjected to a series of shaking table tests at LNEC, Lisbon, Portugal. The paper contains the description of the geometry and construction of the house and all the aspects related to the testing procedure, namely the pre-design, the setup, instrumentation and the testing process itself. The shaking table tests were carried out with a scaled spectrum of the Montenegro (1979) earthquake, at increasing levels of PGA, starting from $0.07 \mathrm{~g}$, moving on to $0.28 \mathrm{~g}$ and finally $0.5 \mathrm{~g}$. The log house did not suffer any major damage and remained in working condition throughout the entire process. The preliminary analysis of the overall behaviour of the log house is also discussed.
\end{abstract}

Keywords: log house, timber, shaking table, seismic performance, numerical modelling 


\section{Introduction}

Log house construction is one of the foremost practices of building with wood that continues to exist even in present times, although to a much lesser extent. In the rudimentary stages, log houses were simple box-like enclosures with minimal openings and consisted of inter-connected walls composed of horizontally stacked logs. With time, notching techniques and log profiles have been refined. There have been advances in carpentry joints and the development of new and enhanced mechanical fasteners has facilitated more efficient adjacent log connections, sill log-foundation connections as well as cross-wall connections. The upshot of these developments is that modern log houses are stronger and more durable structures, with improved stability. However, despite the fact that the practice of building log houses has existed since a very long time, the amount of data available on their seismic behaviour and load resistance mechanisms is limited (Hirai et al., 2004; Vasconcelos et al., 2011). As an example, no specific design guidelines for log houses have been outlined in the Eurocodes. The Log Building Standards published by the International Log Builders Association (2000) only deals with common construction for log walls, notches, joists and roof systems but does not outline any seismic or wind design procedure.

For log shear walls, resistance to lateral loads comes from the interlock between logs, wood or steel dowels, vertical through-bolts or anchor bolts and friction between logs due to vertical loads (National institute for land and infrastructure management et al., 2003).In order to ensure adequate seismic resistance, the sill-log must be firmly connected to the foundation, so that uplift is eliminated and friction and interlocking mechanisms can come into play (Hahney, 2000).Current building codes only consider that the compression perpendicular to the grain and shear stress at intersections between walls are responsible for the in-plane resistance. Since the exact contribution to resistance by friction and interlock between logs cannot be quantified with current knowledge, friction is not considered as a mechanism (Branco and Araujo, 2012).The lateral load transfer mechanism and the energy dissipation characteristics of handcrafted log walls with different configurations has been studied by subjecting them to quasi-static cyclic and non-linear static pushover tests (Popovski, 2002). In the experiments by Graham et al. (2010), the behaviour of log shear walls under racking loads was analyzed and the log walls were found to have a higher resistance than conventional light-frame shear walls. With the view of increasing the understanding of the seismic performance of log houses, a combination of experimental and numerical approaches was adopted in this research campaign. 


\section{Prior work}

A number of experimental tests were carried out as part of the procedure to secure the European Technical Approval (ETA) (2002) of the log house system adopted by Rusticasa ${ }^{\circledR}$. During this process, the individual structural components of the building system were studied and the lateral load resistance mechanisms seen in Figure 1 were evaluated.

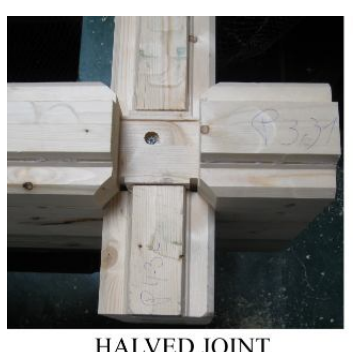

HALVED JOINTT (crosswall intersections)

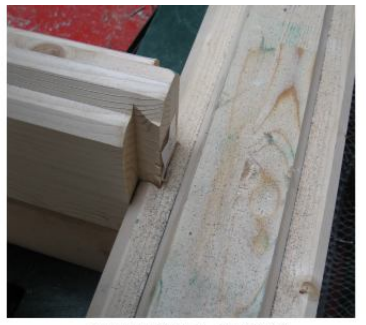

DOVETAIL JOINT (between interior and exterior wall intersection)

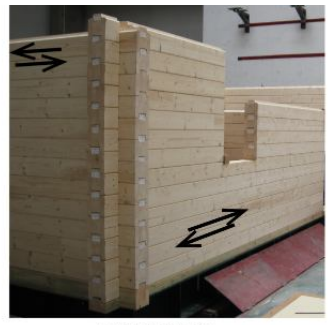

FRICTION

(between log courses)

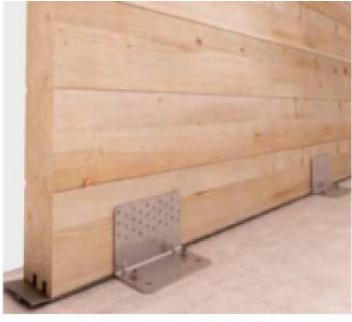

ANCHOR PLATES (connection between sill-log and foundation)

Figure 1: Lateral load resistance mechanisms in log shear walls

The first set of tests was performed on the logs to determine the values of compression strength perpendicular to grain and bending strength (Branco and Cruz, 2008) according to the procedure outlined in EN 408:2010. This was followed by a series of shear and tensile tests under cyclic loading to investigate the behaviour of connections between the sill log and the foundation. In the system angle connectors spaced $1.5 \mathrm{~m}$ apart are used to connect the sill $\log$ with the foundation. Each connector (BMF 40314) has three screws $(5 \times 50 \mathrm{~mm})$ embedded in the log and two metal anchors (M8) embedded in the foundation. The resistance of the connection was calculated to be $3.57 \mathrm{kN}$ as per the expressions given in Eurocode 5 (EN 1995-1-1:2004). The shear tests revealed that the connections possessed good ductility and energy dissipation capacity. From the load-displacement graph obtained during the tensile tests, it was found that the maximum load value increased in accordance with the cyclic value until a displacement of $15 \mathrm{~mm}$, after which it decreased.

In order to study the effect of friction forces between adjacent logs, wall specimens consisting of five overlapped logs of $120 \mathrm{~mm}$ thickness were used. The specimens were subjected to different values of vertical pre-compression $(10,30,50$ and $70 \mathrm{kN})$. A relationship between the maximum load(y) and precompression value(x) was established: $y=0,3389 x+2,2685(k N)$ with an $R^{2}$ value of 0,998 . The high levels of energy dissipation were attributed to the friction resistance. 
The next step was to study the in-plane behaviour of log walls subjected to lateral loads. Full-scale wall specimens with cross wall intersections were subjected to monotonic and cyclic tests. The transversal stiffness, vertical pre-compression, slenderness ratio and foundation connection were varied. Based on the results of the monotonic tests, it was found that the transversal stiffness influences the ultimate load and that the level of vertical pre-compression is proportional to the stiffness. While the foundation type had no influence on the results of the monotonic tests, it did have an influence on the results of the cyclic tests. The specimens where the cross walls were fixed to a steel frame performed better than the specimens with the traditional foundation connection. The lateral resistance of the wall specimens increased with the vertical pre-compression value and decreased with an increase in the slenderness ratio.

An overall seismic analysis of a typical Rusticasa ${ }^{\circledR} \log$ house was carried out based on the results obtained from the experiments conducted previously. The numerical model that was developed pointed out the need for an improved connection system between the logs as well as the connection between the sill log and foundation. Since seismic forces are highest at the base of the log house, it is essential that the connection between the sill log and the foundation is secure (Scott et al., 2005). While previously, the system under study relied only on the orthogonal connections between logs for resistance to loads, the introduction of metal fasteners connecting the logs was advised. Instead of an anchor plate between the wall and the foundation, the use of anchor bolts was recommended (Branco and Araujo, 2012). Both types of foundation connections can be seen in Figure 2. 

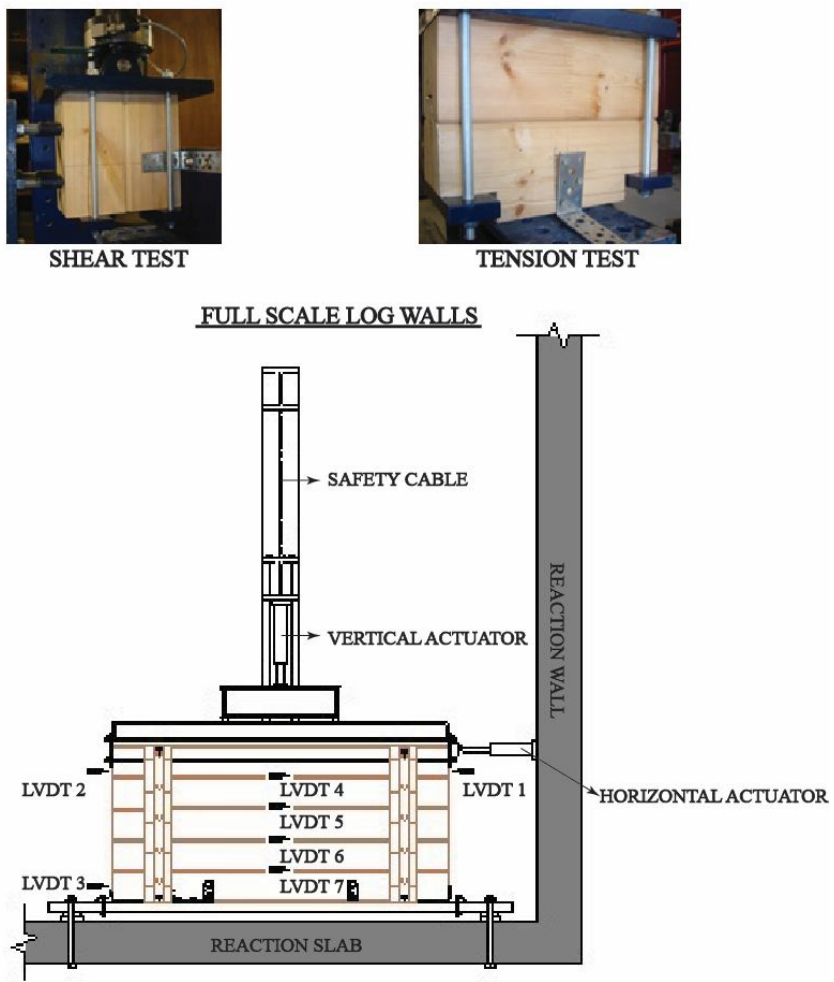

Figure 2: Set-up for tests on individual components of the log house (Branco \& Araujo, 2012; adapted)

The present and final research phase addresses the understanding of the global behaviour of the structure when subjected to seismic loads, its dynamic properties and the interaction of the individual components inside the real structure during an earthquake. The test campaign consists of a series of shaking table tests conducted on a full-scale two-storey log house at LNEC (National Laboratory of Civil Engineering) in Lisbon, Portugal.

\section{Experimental campaign}

\subsection{Description of the test building}

The log house used in the current research experiment has been designed by the Portuguese company Rusticasa ${ }^{\circledR}$. The house is characterized by a rectangular plan of size $5.64 \mathrm{~m} \times 7.3 \mathrm{~m}$ and is symmetrical in the longitudinal direction but asymmetrical in the transverse direction. Its height measures $5.28 \mathrm{~m}$ at the ridge and $4.4 \mathrm{~m}$ at the edges, forming a gable roof. The logs used in the construction of the walls are made from glued laminated timber of Scots Pine trees (Pinus sylvestris L.) and belong to the C24 class of resistance as per EN 388:2009. The mechanical properties of the lamellas were obtained using 
EN 1194:1999. The logs form a perfect fit with each other as they are grooved both at the top and bottom. The dimensions of the cross sections of the logs used are $160 \mathrm{~mm} \times 160 \mathrm{~mm}$ and $80 \mathrm{~mm} \times 160 \mathrm{~mm}$ in the outer and inner walls respectively. The floor and the roof beams are superposed by $22 \mathrm{~m}$ thick Oriented Strand Board (OSB) studded panels in order to ensure rigid in-plane behaviour. Figure 3 shows the 3D structure of the house.

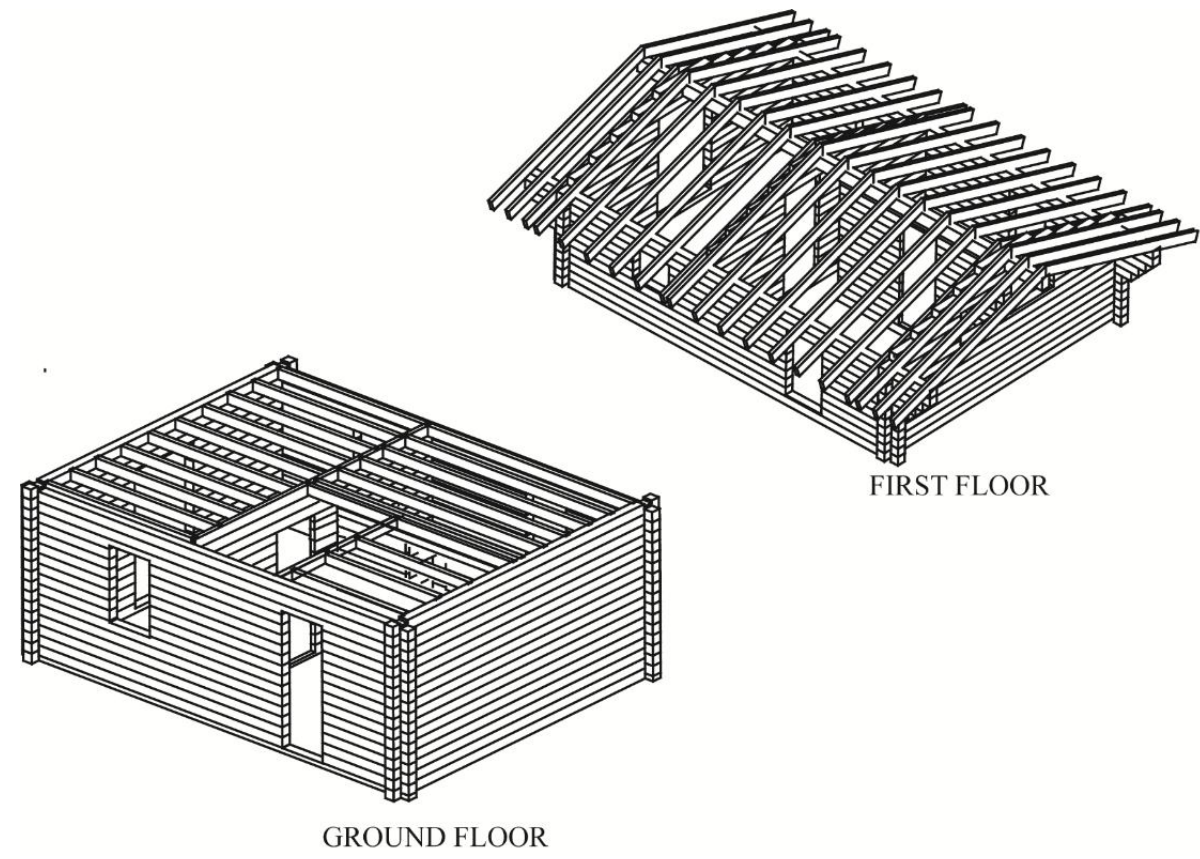

Figure 3: 3-dimensional structure of the log house showing the ground floor and first floor

All the walls of the building have been provided with openings to study their influence on the seismic behaviour of the house. In the case of walls provided with openings on both floors, they are aligned one above the other, either as doors or windows. The ground floor plan can be seen in Figure 4. The external walls in the longitudinal direction (W2 and W4) have identical openings, with a window and a door on the ground floor and two windows in the upper storey. One of the external walls in the transverse direction (W1) has a door provided on each floor while the other one (W3) has two windows provided on the upper floor. Both internal walls (W5 and W6) are provided with a door on each floor. The inner wall in the longitudinal direction is connected with the exterior wall (W3) only along one edge to minimize the effect of wall linkages. 


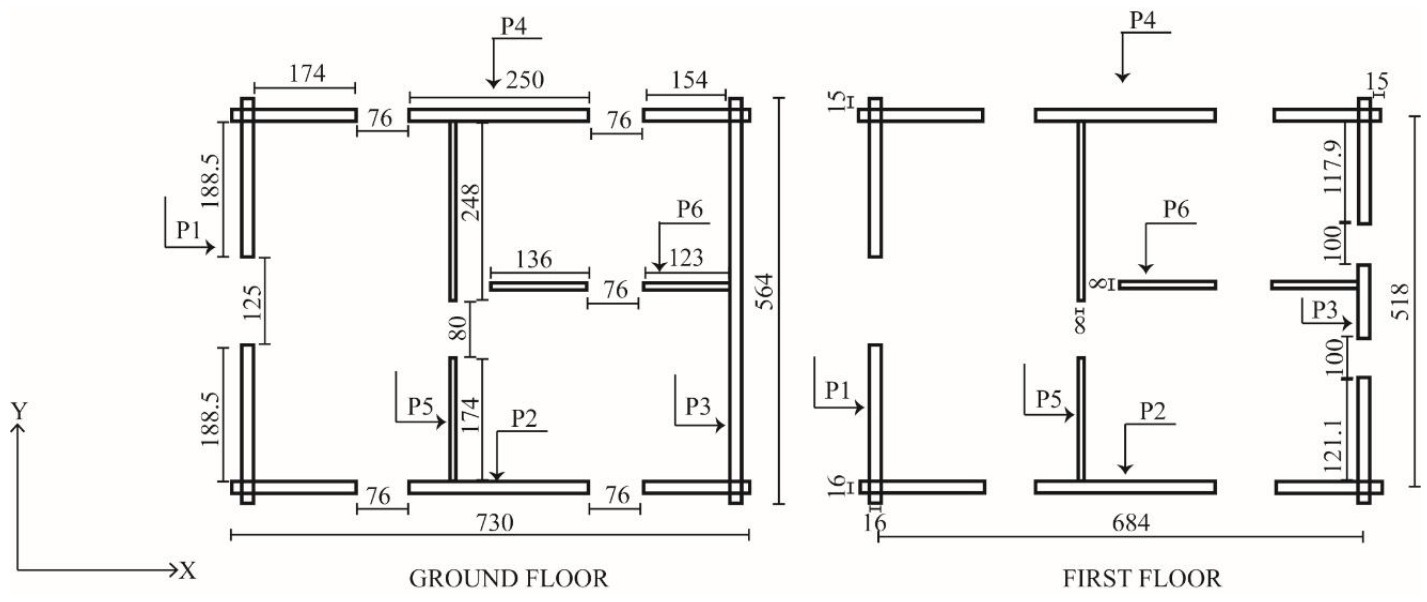

Figure 4: Floor plans of the $\log$ house (all dimensions in $\mathrm{cm}$ )

Since a typical log-house does not dissipate a large amount of energy, the value of the behaviour factor $q$ was assumed to be 2 taking into account the dissipative action contributed by friction as well (Toratti, 2001). In order to simulate real-life loading conditions, additional masses in the form of four steel platforms weighing $600 \mathrm{~kg}$ each and 398 steel plates, weighing $7.1 \mathrm{~kg}$ each, were placed on the inter-storey floor and the roof, respectively.

As in other timber constructions, connections are important in log houses to dissipate energy. Mechanical connectors in the form of screws were provided around the openings, at cross-wall intersections and at the ends of floor and roof beams. The sill logs are connected to the foundation (a steel lattice in this case) through M16 bolts of class 8.8 that are spaced $0.5 \mathrm{~m}$ apart. The sill log-foundation connection is rigid to ensure that sliding is minimal. Apart from mechanical connections, there are halved joints between two intersecting orthogonal logs in the exterior walls and dovetail joints at intersections between logs of exterior walls with interior walls. Ends of the floor joists are also appropriately notched to form dovetail joints with the log walls. These connections can be seen in Figure 5. 


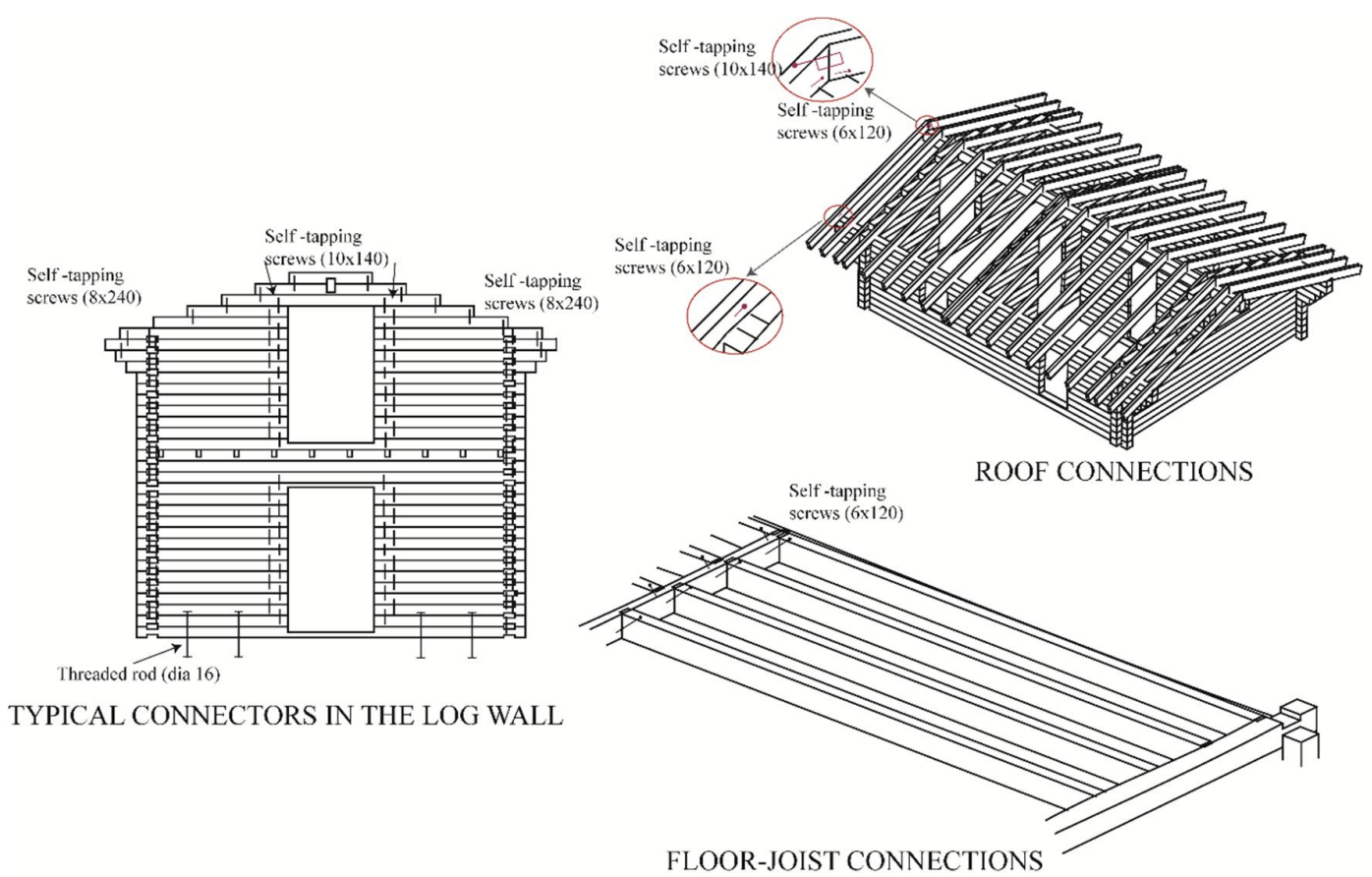

Figure 5: Mechanical connections in the log house (all dimensions in mm)

\subsection{Frequency estimation}

Prior to the seismic test, it was necessary to make an analytical prediction of the expected behaviour of the building during the tests. The design of the test is the key step in the experimental campaign because the seismic input and the parameters required for phase tuning the shaking table are determined based on the model. The test required an accelerogram that would contain frequencies in the vicinity of the frequencies of interest and the control system of the shaking table had to be able to reproduce the motion of the chosen reference in the range of the frequencies of interest.

A numerical model of the building (seen in Figure 6) was developed in SAP2000 to obtain information on the dynamic properties of the structure. One of the challenges faced when modelling timber structures is the definition of the material. With properties differing in the longitudinal, tangential and radial directions, wood is best defined as an orthotropic material. Assuming the material properties obtained from previous numerical and experimental studies performed by the University of Minho (Branco and Araujo, 2012; Branco and Cruz, 2008), wood was modelled as an orthotropic material with different properties along the three principal axes. 


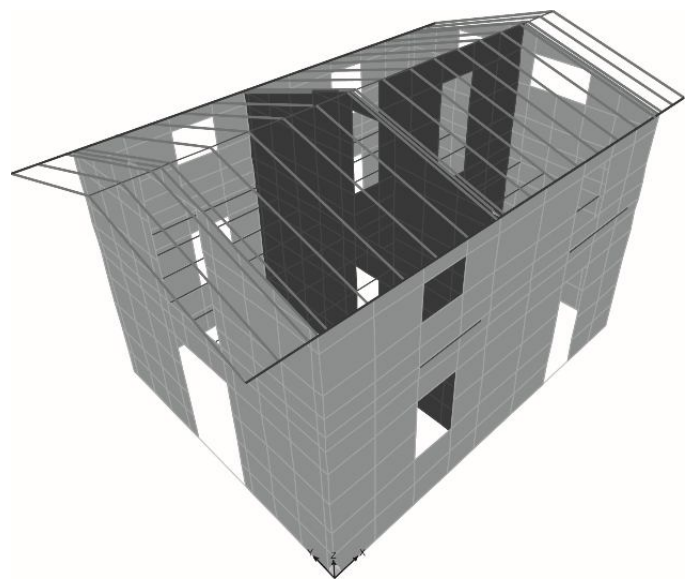

Figure 6: Preliminary numerical model of the log house developed in SAP2000

The logs were represented by shell elements while the floor and roof joists were represented by beam elements. In order to ensure the rigid in-plane behaviour of the floor and roof, diaphragm constraints were assigned to the beams elements existing in those two structural systems. Since the main objective of the model was to get a rough estimate of the modal frequencies, the model was not a sophisticated one. This model neither took into account the effects due to friction nor contribution of the mechanical connections. So the behaviour of the log house model is mainly dependent on the compression stress perpendicular to grain and shear stresses arising at the connections between orthogonal cross walls. The mass of the OSB planks at the inter-storey floor and roof level has been distributed as a uniform load acting on the floor and roof beams, respectively. The additional masses on the roof have been distributed uniformly along the rafters and the additional masses on the inter-storey floor have been uniformly assigned to the floor beams. The value of the modulus of elasticity, E, was assumed to be $2 \times 10^{6} \mathrm{MPa}$ in all directions. Moreover, the values of shear modulus $\mathrm{G}_{13}$ and $\mathrm{G}_{23}$ were assumed to be $20 \mathrm{MPa}$. This was done in order to induce a shear type of behaviour in the house. The value of shear modulus $\mathrm{G}_{12}$ was calculated based on the value of the in-plane stiffness $(K)$ obtained in (Branco and Araujo, 2012) and in the geometry $(h, L$ and $t)$ of the wall specimen tested there.

$$
G_{12}=\frac{K . h}{L . t}=\frac{1289 * 0,75}{1,54 * 0,12}=5231 \mathrm{kN} / \mathrm{m}^{2}
$$

Here, $K$ is the in-plane stiffness $(\mathrm{kN} / \mathrm{m}), h$ is the height of the specimen $(\mathrm{m}), L$ is the length of the specimen (m) and $t$ is the thickness of the specimen (m). 
The values of Poisson's ratio suggested by Bodig and Jayne (1982) for the case of softwoods, have been assumed. The material properties assumed for the wood in the numerical model are presented in Table 1 and 2. The mechanical properties assumed for the floor and roof beams are seen in Table 3 .

Table 1: Values of mechanical properties differing in the orthogonal directions

\begin{tabular}{lccc}
\hline Property & $\mathbf{1 2}$ & $\mathbf{1 3}$ & $\mathbf{2 3}$ \\
\hline \hline Poisson's ratio, $v$ & 0.37 & 0.42 & 0.47 \\
Shear Modulus, G (MPa) & 5.321 & 20 & 20 \\
\hline
\end{tabular}

Table 2: Values of mechanical properties assumed to be constant in the orthogonal directions

\begin{tabular}{lc}
\hline Property & Value \\
\hline Modulus of Elasticity, E (MPa) & 2000000 \\
Density, $\rho\left(\mathrm{kg} / \mathrm{m}^{3}\right)$ & 340 \\
\hline
\end{tabular}

Table 3: Values of mechanical properties of the roof and floor beams

\begin{tabular}{lc}
\hline Property & Value \\
\hline Modulus of Elasticity, E (MPa) & 11000 \\
Density, $\rho\left(\mathrm{kg} / \mathrm{m}^{3}\right)$ & 420 \\
Poisson's ratio, $v$ & 0.37 \\
Shear Modulus, $\mathrm{G}\left(\mathrm{kN} / \mathrm{m}^{2}\right)$ & 690 \\
\hline
\end{tabular}

According to the model, the fundamental frequency of the log house was estimated to be $5.04 \mathrm{~Hz}$ and corresponded to translational movement in the x-direction (longitudinal axis). The second mode was very close to the first mode with a natural frequency of $5.08 \mathrm{~Hz}$ (Testoni, 2012). The first five mode shapes can be seen later in Section 3.6, Figure 12, where a comparison is made with the experimental mode shapes.

\subsection{Construction of the test building}

As the shaking table at LNEC was not large enough to directly accommodate the building, a lattice of steel beams (Figure 7) was used to connect the structure to the table and provide a wider base. The steel lattice consisted of two identical sections of in-plane length $7 \mathrm{~m}$ and in-plane depth $2.65 \mathrm{~m}$ firmly connected to the table by means of steel bars of $36 \mathrm{~mm}$ diameter, making a base of $7 \mathrm{~m} \times 5.3 \mathrm{~m}$ for the building. Each section has two HEA 400 profile beams in the longitudinal direction and three HEA 400 beam profiles 
along with two IPE 400 profile beams in the transverse direction. The building was mounted and assembled directly over the steel lattice. All primary structural elements of the building were prefabricated in a factory at Vila Nova de Cerveira and transported by truck over a distance of about $400 \mathrm{~km}$ to Lisbon. The construction was carried out by three workers and took four days. The stages of assembly can be seen in Figure 8 .

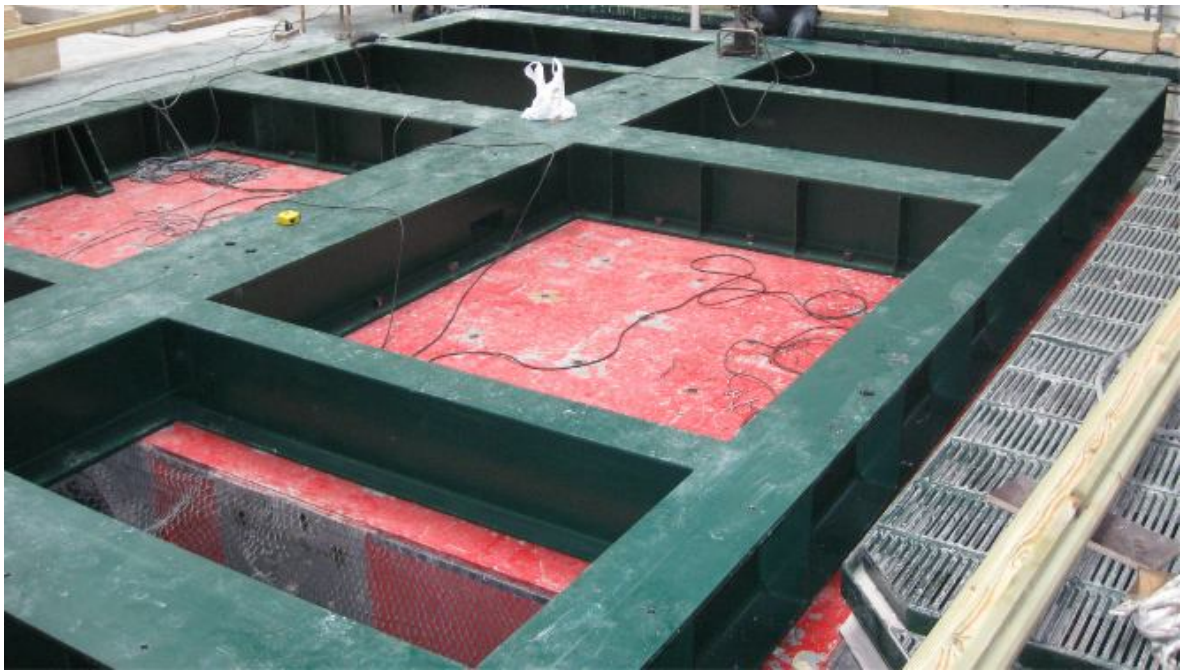

Figure 7: The steel lattice connected to the shaking table
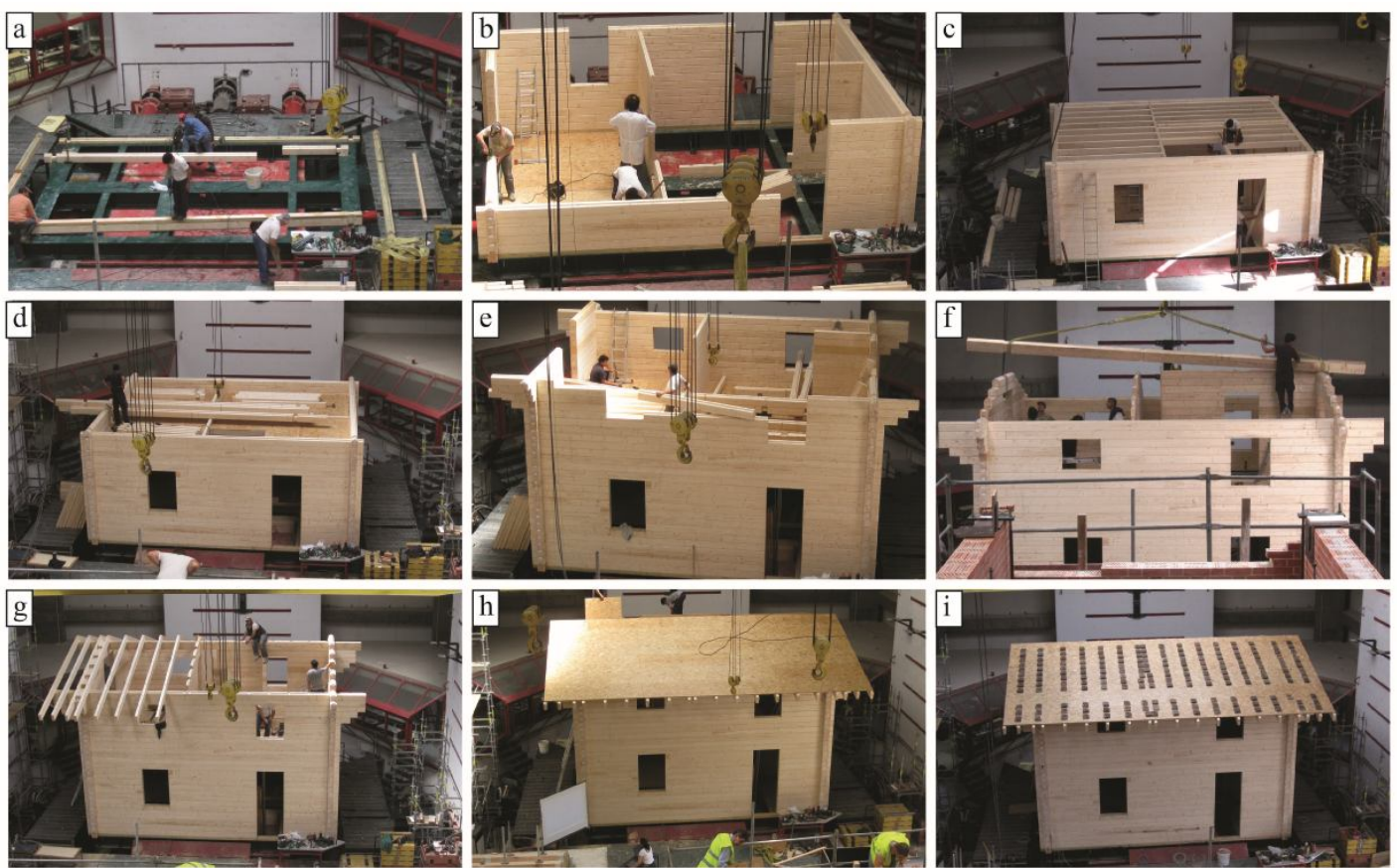

Figure 8: Stages of construction: (a) connecting the sill logs with the steel lattice; (b) laying the ground floor walls; (c) placing the inter-storey floor beams; (d) nailing OSB planks to the floor joists; (e) laying the first floor walls; (f) positioning the ridge board; (g) connecting the rafters; (h) placing the OSB sheaths over the roof; (i) completed house with additional weights 


\subsection{Instrumentation}

Once the house was constructed, the next step was to place the instruments to monitor the accelerations, wall slippage and uplift, shear deformations, inter-storey displacements and forces in the building components. A total of 80 instruments were placed at different points of interest in the building. The instruments were arranged to assess the behaviour of the building in the longitudinal and transverse directions, and focused on observing the behaviour of five wall sections on the ground floor, two in the longitudinal direction and three in the transverse direction. The different instruments used to collect information on the forces and deformations of the building are seen in Figure 9. The data obtained during all the stages of testing right from the tuning of the shaking table to the dynamic identification of the building and the seismic tests were sampled at a sampling frequency of $125 \mathrm{~Hz}$.
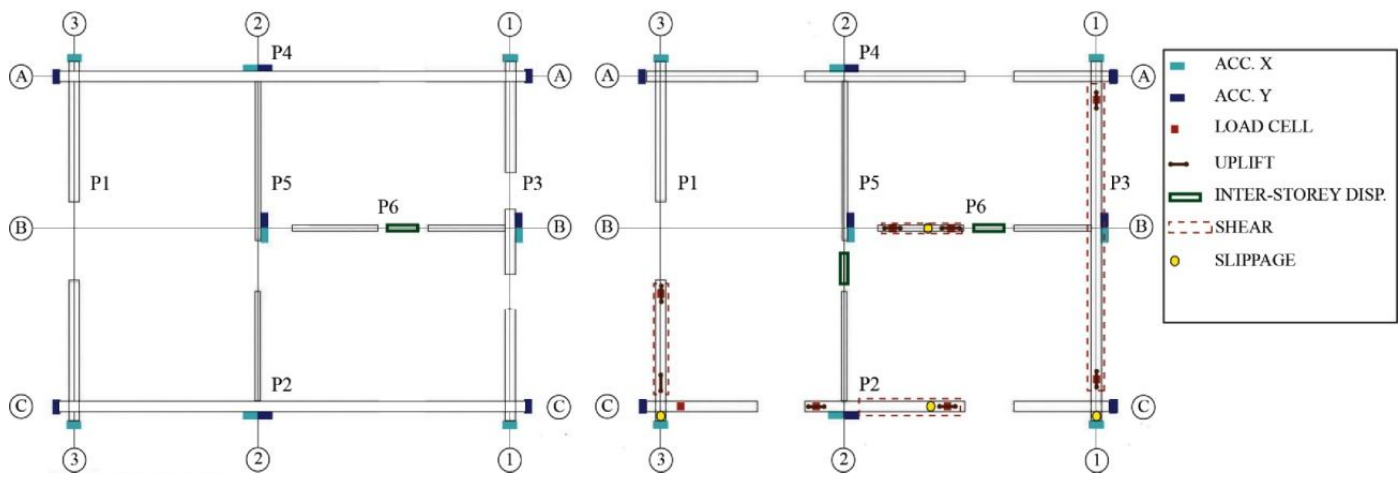

Figure 9: Instrumentation layout

\subsection{Shaking table test procedure}

Once all measuring instruments were set-up, the following tasks were performed: calibration of the instruments, dynamic characterization tests and shaking table tests. The dynamic characterization tests were of low intensity, while the seismic tests were carried out with increasing levels of Peak Ground Acceleration (PGA).White noise was used as input in the case of the characterization tests. The acceleration time history was characterized by a Gaussian distribution of RMS level of $0.05 \mathrm{~g}$ and the frequency ranged between $0.1 \mathrm{~Hz}$ and $30 \mathrm{~Hz}$. The purpose of these tests was to calibrate the parameters necessary to control the shaking table and to conduct the dynamic identification of the structure. A first frequency evaluation test was performed to identify the fundamental period, mode shapes and damping of the structure. In this stage, a 
fundamental period of $\mathrm{T}=0.185 \mathrm{~s}(\mathrm{f}=5.389 \mathrm{~Hz})$ was obtained. The mode was a mixed mode, with movement along the longitudinal as well as the transverse directions.
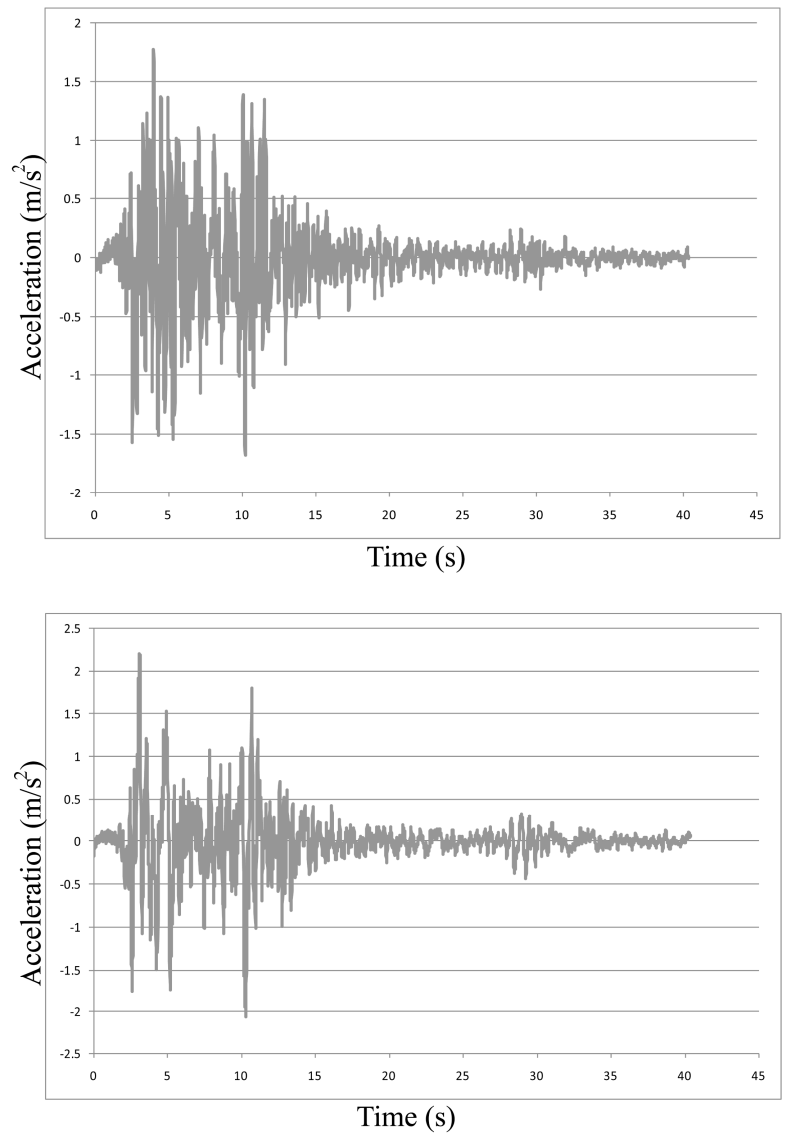

Figure 10: The unscaled accelerograms of the Montenegro earthquake recorded at the Ulcinj- Hotel Albatros station used in the transverse (top) and longitudinal (bottom) directions

The seismic testing procedure that followed was carried out with three different PGA values - 0.07g, $0.28 \mathrm{~g}$ and $0.5 \mathrm{~g}$. To replicate the effect of an earthquake of a longer duration (the Montenegro earthquake has an intense phase of only about 10s), the seismic tests of different intensities were carried out multiple times. Despite this, there was no major damage observed in the structure. After the first dynamic identification test was performed, four shaking table tests were carried out with a PGA of $0.07 \mathrm{~g}$. This was followed by another dynamic identification test to determine any changes in the natural frequency of the structure. The PGA was then increased to $0.28 \mathrm{~g}$ and three seismic tests were carried out until a pronounced sliding of logs was seen in the window of one of the walls of the house. After this, a dynamic identification test was done and the building was subjected to two more seismic tests of $0.28 \mathrm{~g}$ PGA. Finally two tests 
with a PGA of $0.05 \mathrm{~g}$ were conducted on the log house, which were preceded and followed by dynamic identification tests.

A comparison between the mode shapes and frequencies is seen in Figure 11 as well as Table 4. The fundamental frequency of the log house was determined to be $5.39 \mathrm{~Hz}$ while the numerical model predicted a value of $5.04 \mathrm{~Hz}$ for the first mode and $5.08 \mathrm{~Hz}$ for the second mode.
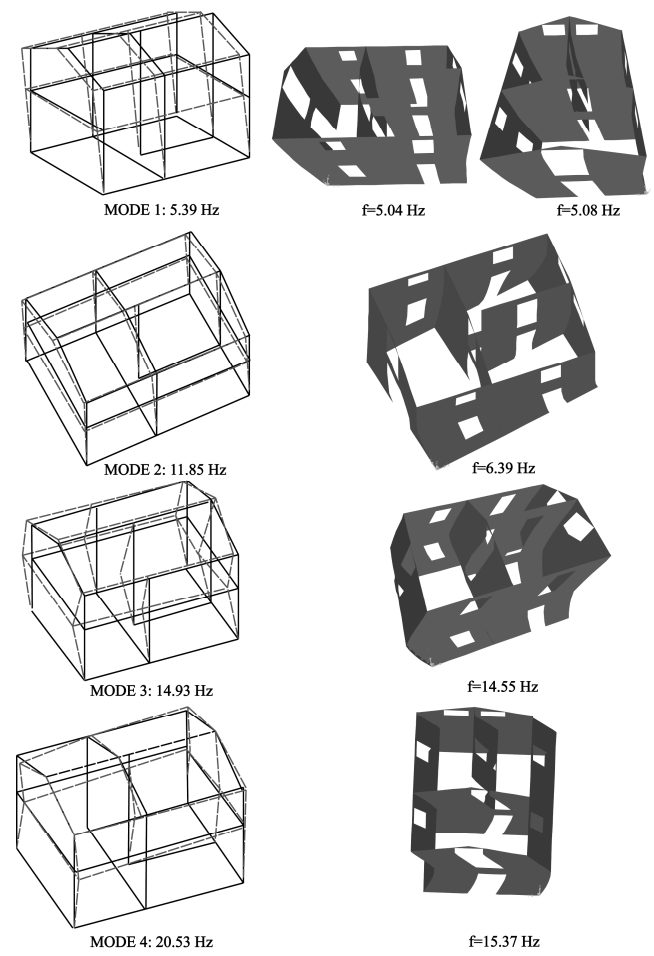

$\mathrm{f}=15.37 \mathrm{~Hz}$

Figure 11: Outlines of the mode shapes obtained during the experiments (left) and the predicted mode shapes (right)

Table 4: Comparison between the experimental and predicted modal properties of the log house

\begin{tabular}{lcccccc}
\hline \multicolumn{3}{c}{ Experimental modes } & \multicolumn{3}{c}{ Predicted modes } \\
\hline No. & Description & Frequency $(\mathbf{H z})$ & Period (s) & Description & Frequency (Hz) & Period (s) \\
\hline & & & Translation-Y & 5.04 & 0.198 \\
1 & Mixed mode & 5.39 & 0.186 & Translation-X & 5.08 & 0.197 \\
2 & Translation-X & 11.85 & 0.084 & Torsional & 6.39 & 0.156 \\
3 & Torsional & 14.93 & 0.067 & Translation $-\mathrm{X}$ & 14.55 & 0.069 \\
4 & Translation-Y & 20.53 & 0.049 & Translation- Y & 15.37 & 0.065 \\
\hline
\end{tabular}




\subsection{Damages observed}

There was no damage observed for the tests carried out with the lowest scaled spectrum of the Montenegro (1979) earthquake (0.07g PGA). The only damage that was noticed after the $0.28 \mathrm{~g}$ tests was the sliding of the logs in the North Western corner of the house, located near the window in wall W3. There was some more minor damage observed after the PGA was increased to $0.5 \mathrm{~g}$. No kind of repair intervention was carried out between the successive stages of the experiment. The following damage was observed at the end of all the tests: fracture along the grain of the log due to out-of-plane flexure, fracture along the grain at connections between orthogonal walls due to shear, internal cracks in the log section and fracture at the top and bottom notches of the logs. The typical damages can be seen in Figure 12.
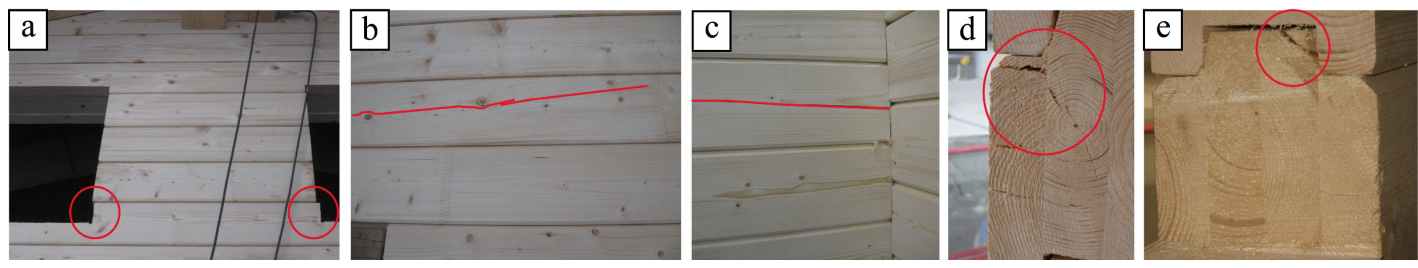

Figure 12: Damage observed after completion of all tests: (a) slipping of logs in the NW part of the house; (b) fracture along the grain of the logs; (c) splitting of logs at cross wall intersections; (d) internal cracks seen in the $\log$ cross section; (e) damage seen at the top notch of a $\log$

\section{CONCLUSIONS}

The above tests were performed within the framework of the SERIES Project 'Multi-storey timber buildings', that involved research groups from the University of Trento, Italy, the University of Minho, Portugal and TU Graz, Austria, in collaboration with LNEC, Portugal. In spite of repeated shaking table tests and a strong input of $0.5 \mathrm{~g}$, the integrity of the log house was hardly affected. The good seismic performance can be attributed to the carpentry joints, the positioning of the mechanical fasteners around the openings and at the cross-wall corners, the contact between log courses facilitated by the grooves in the logs and the anchor bolts connecting the sill-log and foundation.

The fast pace and ease of construction and the absence of major damage in the building indicate that this form of log construction would be a viable option in areas that have high seismic hazard. The fundamental frequency obtained was $5.39 \mathrm{~Hz}$ during the initial characterization test and reduced to $5.109 \mathrm{~Hz}$ $[\mathrm{T}=0.196 \mathrm{~s}]$ during the final characterization test. The small difference in the magnitude reinforces the observation that the damages suffered by the log house were minor. The proximity of the values of the first two predicted modes can be attributed to what was seen during the shaking table tests - a combination of 
longitudinal and transverse movements of the entire house during the first mode. Apart from the fundamental mode, there was a discrepancy in the frequency values obtained for the next three modes. This can be attributed to the fact that the numerical model was very simple. The seismic response of the model was mainly due to the compression stresses perpendicular to grain and the shear stresses at the cross wall connections as the model did not account for the contribution of friction and the self-tapping screws. A detailed analysis of the dynamic properties, forces and deformations in the log house will be furnished in an ensuing paper.

\section{ACKNOWLEDGEMENTS}

Acknowledgement to SERIES: The research leading to these results has received funding from the European Union‘s Seventh Framework Programme [FP7/2007-2013] under grant agreement n²27887 (SERIES). 


\section{REFERENCES}

Bodig J and Jayne BA (1982) Mechanics of wood and wood composites. Van Nostrand, New York.

Branco JM and Araujo JP (2012) Structural behaviour of log timber walls under lateral in-plane loads. In Engineering Structures, 40, pp. 371-382. URI: http://hdl.handle.net/1822/19907.

Branco JM and Cruz PJS (2008) Mechanical characterization of glued laminated wood round logs. In Journal of Associação Portuguesa de Análise Experimental de Tensões, Vol 17, pp. 101-108 (in Portuguese). URI: http://www-ext.lnec.pt/APAET/pdf/Rev_17_A11.pdf

EN 1194:1999 (1999) Timber structures. Glued laminated timber. Strength classes and determination of characteristic values. European Committee for Standardisation, CEN, Brussels.

EN 1995-1-1:2004 (2004) Eurocode 5: Design of timber structures - Part 1-1: General - Common rules and rules for buildings. European Committee for Standardisation, CEN, Brussels.

EN 338:2009 (2009) Structural Timber: Strength Classes. European Committee for Standardisation, CEN, Brussels.

EN 408:2010 (2010) Timber structures - Structural timber and glued laminated timber - Determination of some physical and mechanical properties. European Committee for Standardisation, CEN, Brussels.

ETAG 012 (2002) Log Building Kits: Guideline for European Technical Approval. European Organization for Technical Approvals.

Graham DA, Carradine DM, Bender DA and Dolan DJ (2010) Performance of log shear walls subjected to monotonic and reverse-cyclic loading. In Journal of Structural Engineering, ASCE 136 (1), pp. 3745.

Hahney, T. (2000) How Log buildings resist lateral loads. In Log Building News, 32; pp. 1-6.

Hirai T, Kimura T, Yanaga K, Sasaki Y and Koizumi A (2004) Lateral resistances of log constructions. In Proceedings of the $8^{\text {th }}$ World Conference on Timber Engineering WCTE, Lahti, Finland, Vol. III, pp. 251-254.

ILBA (International Log Builders Association) (2000) Log Building Standards. ILBA, Lumby, British Columbia, 17pp.

National institute for land and infrastructure management et al. (2003) Technical standard and design examples for log constructions. Kogaku Tosho. 
Popovski M (2002) Testing of lateral resistance of handcrafted log walls Phase I and II. Forintek Canada Corp., Vancouver, BC.

SAP 2000. CSI Analysis Reference Manual for SAP2000. Version v15. Computers \& Structures Inc., Berkeley, USA.

Scott RJ, Leichti RJ and Miller HT (2005) An experimental investigation of foundation anchorage details and base shear capacity for log buildings. In Forests Products Journal, Vol. 55, Issue 4, pp. 38-45.

Testoni M (2012) Shaking table test of a building wood log house: design and execution, Master's thesis, University of Trento, Italy (in Italian).

Toratti T (2001) Seismic Design of Timber Structures. VTT Building and Transport, Espoo.

Vasconcelos G, Poletti E, Salavessa E, Jesus AMA, Lourenço PB and Pilaon P (2011) In-plane shear behaviour of tradition timber walls. In Proceedings of the International Conference on structural health assessment of timber structures SHATIS'11, Lisbon, Portugal. 